\title{
Eficiência de coeficientes de similaridade em genótipos de feijão mediante marcadores RAPD(1)
}

\author{
Beatriz Marti Emygdio(2), Irajá Ferreira Antunes( ${ }^{(3)}$, Eva Choer ${ }^{(3)}$ e Jorge Luiz Nedel(4)
}

Resumo - O objetivo deste trabalho foi avaliar a eficiência de coeficientes de similaridade em genótipos de feijão por meio de marcadores RAPD. A eficiência dos coeficientes de similaridade de Jaccard, Sorensen-Dice, Russel e Rao, Ochiai, Coincidência Simples, Rogers e Tanimoto, Hamann, Kulczynski 2, Yule e Phi no agrupamento de 35 cultivares locais e comerciais de feijão foi analisada com base em 104 marcadores RAPD. Os coeficientes foram comparados por dendrogramas, pela eficiência da projeção no espaço bidimensional e por grupos formados pelo método de otimização de Tocher. Os diferentes coeficientes de similaridade apresentaram variação quanto à eficiência de projeção no espaço bidimensional e quanto ao número de grupos formados pelo método de otimização de Tocher. Os coeficientes de Russel e Rao e de Yule são os mais discordantes, e os coeficientes de Sorensen-Dice, Ochiai e Kulczynski 2 são mais eficientes que os demais. O coeficiente de Russel e Rao não tem a capacidade de agrupar as cultivares em seus respectivos centros de domesticação.

Termos para indexação: Phaseolus vulgaris, divergência genética, análise de agrupamento.

\section{Efficiency of similarity coefficients based on RAPD markers in common bean genotypes}

\begin{abstract}
The objective of this work was to evaluate the efficiency of similarity coefficients of bean genotypes based on RAPD markers. The efficiency of Jaccard, Sorensen-Dice, Russel and Rao, Ochiai, Simple Maching, Rogers and Tanimoto, Hamann, Kulczynski 2, Yule and Phi coefficients in the clustering and ordination of 35 common bean genotypes was evaluated through 104 RAPD markers. The coefficients were compared by the evaluation of dendrograms, projection efficiency in bidimensional space and groups formed using Tocher's optimization method. The different similarity coefficients altered the projection efficiency in a two-dimensional space and formed different number of groups by Tocher's optimization procedure. Among these coefficients, Russel and Rao and Yule's are the most discordants, and the Sorensen-Dice, Ochiai and Kulczynski 2 present the higher efficiency. Russel and Rao coefficient is not able for separating bean cultivars according to domestication centers.
\end{abstract}

Index terms: Phaseolus vulgaris, genetic divergence, cluster analysis.

\section{Introdução}

Cultivares melhoradas oriundas de programas de melhoramento, denominadas cultivares comerciais para fins deste estudo, e cultivares locais, tradicio-

\footnotetext{
(1) Aceito para publicação em 6 de novembro de 2002 .

Extraído da tese de doutorado apresentada pelo primeiro autor à Universidade Federal de Pelotas (UFPel), Pelotas, RS.

(2) Embrapa-Centro Nacional de Pesquisa de Trigo, Caixa Postal 451, CEP 99001-970 Passo Fundo, RS. E-mail: bemygdio@cnpt.embrapa.br

(3) Embrapa-Centro de Pesquisa Agropecuária de Clima Temperado, Caixa Postal 403, CEP 96001-970 Pelotas, RS. E-mail: iraja@cpact.embrapa.br, choer@cpact.embrapa.br

(4) UFPel, Fac. de Agronomia, Caixa Postal 354 , CEP 96010-900 Pelotas, RS. E-mail: jlnedel@ufpel.tche.br
}

nalmente cultivadas por pequenos agricultores, constituem o pool gênico primário, disponível para hibridização em programas de melhoramento (Harlan \& De Wet, 1971). O conhecimento da diversidade genética entre as cultivares comerciais e entre estas e as locais é extremamente útil aos melhoristas por permitir melhor organização dos recursos genéticos e melhor aproveitamento da diversidade genética disponível.

Diferentes métodos filogenéticos têm sido empregados no estudo da divergência genética e caracterização da diversidade entre e dentro de espécies vegetais. Tais métodos variam conforme o tipo de informação considerada, como as características morfológicas, fisiológicas, ecológicas e as características genético-moleculares (Diniz Filho, 2000). 
As características moleculares mais comumente usadas até início da década de 90, em espécies vegetais de interesse agronômico, eram isoenzimas e proteínas. A partir de então, marcadores moleculares do tipo RAPD (Random Amplified Polymorphic DNA) passaram a predominar em estudos de caracterização de germoplasma (Tingey et al., 1993).

Em feijão, diferentes coeficientes de similaridade têm sido usados, a partir de marcadores RAPD, na análise de relações genéticas entre diferentes cultivares ou acessos. Skroch et al. (1998) usaram o coeficiente de Jaccard no estudo comparativo de coleções mexicanas de germoplasma de feijão. Johns et al. (1997) usaram o coeficiente de Coincidência Simples na classificação do pool gênico de cultivares locais de feijão do Chile. No cálculo das distâncias genéticas entre cultivares de feijão de diferentes raças, Duarte et al. (1999) usaram o coeficiente de Sorensen-Dice.

Além do grande número de coeficientes de similaridade encontrados na literatura, é possível observar diferentes coeficientes sendo utilizados com o mesmo propósito, assim como os mesmos coeficientes sendo aplicados com propósitos diferentes. No entanto, nem todos os autores justificam a razão da escolha de determinado coeficiente. Segundo Jackson et al. (1989), a escolha subjetiva do método de agrupamento ou coeficiente de similaridade pode causar problemas, comprometendo a natureza da análise.

Duarte et al. (1999) compararam oito coeficientes de similaridade, baseados em marcadores RAPD, em feijão, e constataram que o emprego de diferentes coeficientes causou poucas alterações no agrupamento das cultivares. Resultados semelhantes foram encontrados por Johns et al. (1997). Já Rocha (2000) comparou oito coeficientes de similaridade por meio de marcadores RAPD em batata e não observou alteração no agrupamento dos genótipos estudados.

O agrupamento dos genótipos a partir dos diferentes coeficientes de similaridade depende do modo pelo qual a matriz de dados originais (1: presença e 0: ausência) é empregada na estimativa da similaridade. Quando dois genótipos são comparados ocorrem as seguintes situações: $a=1,1 ; b=1,0 ; c=0,1$ e $\mathrm{d}=0,0$. Assim, conforme os diferentes pesos dos valores de (a), (b), (c) e (d) atribuídos pelos diferentes coeficientes e o modo pelo qual são considerados, o agrupamento dos genótipos pode ser influenciado.

O objetivo deste trabalho foi analisar a eficiência de coeficientes de similaridade, em genótipos de feijão por meio de marcadores RAPD.

\section{Material e Métodos}

Coeficientes de similaridade foram comparados entre 22 cultivares locais de feijão coletadas entre produtores, em diversas regiões do Rio Grande do Sul, e 13 cultivares comerciais, indicadas pela pesquisa para cultivo no Estado, analisadas por marcadores RAPD (Tabela 1). O DNA

Tabela 1. Características das cultivares locais e comerciais de feijão cultivadas no Rio Grande do Sul e utilizadas no estudo de comparação entre coeficientes de similaridade.

\begin{tabular}{|c|c|c|c|}
\hline \multirow[t]{2}{*}{ Cultivares } & \multirow{2}{*}{$\begin{array}{c}\text { Centro de } \\
\text { domesticação }\end{array}$} & \multicolumn{2}{|l|}{ Semente } \\
\hline & & Cor & $\begin{array}{l}\text { Peso } \\
(\mathrm{g})^{(1)}\end{array}$ \\
\hline \multicolumn{4}{|l|}{ Locais } \\
\hline 05 OP PP & Mesoamericano & Preta & 14,4 \\
\hline 06 OP M & Mesoamericano & Preta & 16,5 \\
\hline 14 OP MP & Mesoamericano & Preta & 17,8 \\
\hline $15 \mathrm{OP}$ EN & Mesoamericano & Preta & 15,5 \\
\hline $24 \mathrm{OP}$ & Mesoamericano & Preta & 13,9 \\
\hline 25 BR M & Mesoamericano & Preta & 18,6 \\
\hline 26 OP P & Mesoamericano & Preta & 14,6 \\
\hline 30 OP P & Mesoamericano & Preta & 13,9 \\
\hline $36 \mathrm{BR} \mathrm{MP}$ & Andino & Preta & 35,7 \\
\hline $39 \mathrm{BR}$ & Andino & Preta & 34,0 \\
\hline $42 \mathrm{AM}$ & Andino & Vinho & 32,7 \\
\hline $45 \mathrm{MO}$ & Andino & Cinza/preta ${ }^{(2)}$ & 32,9 \\
\hline 54 OP M & Mesoamericano & Preta & 15,7 \\
\hline $55 \mathrm{OP} \mathrm{EN}$ & Mesoamericano & Preta & 15,3 \\
\hline $56 \mathrm{OP}$ & Mesoamericano & Preta & 19,2 \\
\hline $57 \mathrm{OP}$ & Mesoamericano & Preta & 15,6 \\
\hline $58 \mathrm{OP} P$ & Mesoamericano & Preta & 15,0 \\
\hline 60 OP P & Mesoamericano & Preta & 18,9 \\
\hline 60 OP M & Mesoamericano & Preta & 17,3 \\
\hline 61 OP P & Mesoamericano & Preta & 17,3 \\
\hline $61 \mathrm{OP} M$ & Mesoamericano & Preta & 19,5 \\
\hline $62 \mathrm{MO}$ & Andino & Vermelha/preta $^{(2)}$ & 35,2 \\
\hline \multicolumn{4}{|l|}{ Comerciais } \\
\hline Rio Tibagi & Mesoamericano & Preta & 13,6 \\
\hline Guateian 6662 & Mesoamericano & Preta & 13,7 \\
\hline Macanudo & Mesoamericano & Preta & 15,3 \\
\hline Minuano & Mesoamericano & Preta & 18,6 \\
\hline Iapar 44 & Mesoamericano & Preta & 16,8 \\
\hline Macotaço & Mesoamericano & Preta & 13,3 \\
\hline Guapo Brilhante & Mesoamericano & Preta & 8,2 \\
\hline FT Nobre & Mesoamericano & Preta & 18,1 \\
\hline FT 120 & Mesoamericano & Preta & 16,2 \\
\hline Carioca & Mesoamericano & Creme/havana ${ }^{(2)}$ & 20,7 \\
\hline Iraí & Andino & Areia/vinho $^{(2)}$ & 37,6 \\
\hline FT 206 & Mesoamericano & Creme/havana ${ }^{(2)}$ & 19,1 \\
\hline Iapar 31 & Mesoamericano & Creme/havana ${ }^{(2)}$ & 19,8 \\
\hline
\end{tabular}

Pesq. agropec. bras., Brasília, v. 38, n. 2, p. 243-250, fev. 2003 
genômico foi extraído de tecido foliar, a partir de dez plantas por genótipo, coletadas em casa de vegetação na Embrapa-Centro de Pesquisa Agropecuária de Clima Temperado, RS. Os procedimentos usados na extração de DNA, reações de amplificação e separação dos fragmentos amplificados por eletroforese em gel de agarose foram descritos por Ferreira \& Grattapaglia (1998), exceto em relação à concentração do gel, que foi de $1,4 \%$.

Na comparação da eficiência dos coeficientes de similaridade, foi construída uma matriz de dados, a partir de 104 bandas RAPD, com atribuição de escores baseada na presença (1) e na ausência (0) de bandas. Estimativas de similaridade genética $\left(\mathrm{sg}_{\mathrm{ij}}\right)$, entre cada par de cultivares $\mathrm{i}$ e $\mathrm{j}$ foram feitas para dez coeficientes de similaridade (Tabela 2). Similaridades derivadas desses coeficientes foram transformadas em medidas de distância genética $\left(\mathrm{dg}_{\mathrm{ij}}\right)$ pela seguinte equação: $\mathrm{dg}_{\mathrm{ij}}=1-\mathrm{sg}_{\mathrm{ij}}$. Todas as matrizes de similaridade foram ao encontro das pressuposições para transformação em distâncias genéticas, isto é, foram definidas como não negativas (Johnson \& Wichern, 1998, citado por Duarte et al., 1999). As análises de similaridade foram feitas a partir do programa NTSYS (Numerical Taxonomy and Multivariate System) Versão 1.7 (Rohlf, 1992).

O método da média aritmética não ponderada (UPGMA) e o agrupamento seqüencial, aglomerativo, hierárquico e exclusivo (SAHN) foram empregados na construção dos dendrogramas. O número ótimo de grupos foi determinado segundo metodologia descrita por Milligan \& Cooper (1985).

No estabelecimento de grupos de cultivares com o mesmo padrão de similaridade, em relação a cada coeficiente estudado, utilizou-se o método aglomerativo de otimização de Tocher. Este realiza a partição do conjunto de genótipos (cultivares) em subgrupos não vazios e mutuamente exclusivos, por meio da maximização ou minimização de alguma

Tabela 2. Coeficientes de similaridade analisados, segundo sua eficiência, com base em marcadores RAPD, em feijão.

\begin{tabular}{ll}
\hline Coeficiente & Expressão da similaridade ${ }^{(1)}$ \\
\hline Jaccard & $\mathrm{a} /(\mathrm{a}+\mathrm{b}+\mathrm{c})$ \\
Sorensen-Dice & $2 \mathrm{a} / 2 \mathrm{a}+\mathrm{b}+\mathrm{c}$ \\
Russel e Rao & $\mathrm{a} /(\mathrm{a}+\mathrm{b}+\mathrm{c}+\mathrm{d})$ \\
& $\mathrm{a} / \sqrt{(\mathrm{a}+\mathrm{b})(\mathrm{a}+\mathrm{c})}$ \\
Ochiai & $(\mathrm{a}+\mathrm{d}) /(\mathrm{a}+\mathrm{b}+\mathrm{c}+\mathrm{d})$ \\
Coincidência Simples & $(\mathrm{a}+\mathrm{d}) /[\mathrm{a}+2(\mathrm{~b}+\mathrm{c})+\mathrm{d}]$ \\
Rogers e Tanimoto & {$[(\mathrm{a}+\mathrm{d})-(\mathrm{b}+\mathrm{c})] /(\mathrm{a}+\mathrm{b}+\mathrm{c}+\mathrm{d})$} \\
Hamann & $1 / 2[\mathrm{a} /(\mathrm{a}+\mathrm{b})+\mathrm{a} /(\mathrm{a}+\mathrm{c})]$ \\
Kulczynski & $(\mathrm{ab}-\mathrm{bc}) /(\mathrm{ad}+\mathrm{bc})$ \\
Yule & $(a d-b c) / \sqrt{(a+b)(c+d)(a+b)(b+d)}$ \\
Phi &
\end{tabular}

medida preestabelecida. O método requer a obtenção da matriz de dissimilaridade, sobre a qual é identificado o par de indivíduos mais similar, que formará o grupo inicial (Cruz, 1997).

A projeção das distâncias no espaço bidimensional foi feita a partir do programa GENES (Cruz, 1997). Os coeficientes de similaridade foram comparados pela eficiência de projeção segundo três parâmetros: correlação entre as distâncias originais e as estimadas, obtidas pela representação gráfica da dispersão bidimensional (r), grau de distorção (1- $\alpha$ ) e valor do stress (s), expressos pelas equações:

$$
\alpha=\sum_{\mathrm{i}<\mathrm{j}} \sum_{\mathrm{gij}} \mathrm{d}_{\mathrm{i}<\mathrm{j}} / \sum_{\mathrm{oij}}, \mathrm{s}=\sqrt{\sum_{\mathrm{i}<\mathrm{j}} \sum_{\mathrm{oij}}\left(\mathrm{d}_{\mathrm{gij}}^{2}-\mathrm{d}^{2}\right)^{2} / \sum_{\mathrm{i}<\mathrm{j}} \sum_{\mathrm{oij}}^{2}},
$$

em que: $\mathrm{d}_{\mathrm{gij}}$ e $\mathrm{d}_{\mathrm{oij}}$ são as distâncias gráficas (espaço bidimensional) e originais (espaço $\mathrm{n}$ dimensional), respectivamente, de todos os pares de genótipos i e j.

O stress é um parâmetro que determina a qualidade do ajuste da projeção gráfica, sendo os níveis classificados segundo sugestões de Kruskal (1964), ou seja, para 40\%, $20 \%, 10 \%, 5 \%$ e $0 \%$ de stress, o ajuste será, respectivamente, insatisfatório, regular, bom, excelente e perfeito.

\section{Resultados e Discussão}

Todos os dendrogramas construídos a partir dos coeficientes estudados apresentaram a mesma estrutura geral (Figuras 1e 2). Com exceção do coeficiente de Russel e Rao, todos os outros foram capazes de agrupar as 35 cultivares locais e comerciais de feijão em seus respectivos centros de domesticação, andino e mesoamericano, embora dentro de cada grupo, o ordenamento de algumas cultivares tenha sido alterado.

Johns et al. (1997) também verificaram que diferentes coeficientes de similaridade não afetaram a separação de cultivares locais chilenas de feijão em dois grupos distintos e correspondentes aos centros de domesticação andino e mesoamericano. Da mesma forma, Duarte et al. (1999), a partir de oito coeficientes de similaridade diferentes, conseguiram separar 27 cultivares de feijão nos grupos andino e mesoamericano.

Esses autores, mesmo tendo verificado o agrupamento das cultivares em seus respectivos centros de domesticação, também verificaram pequenas alterações no ordenamento das cultivares dentro desses 

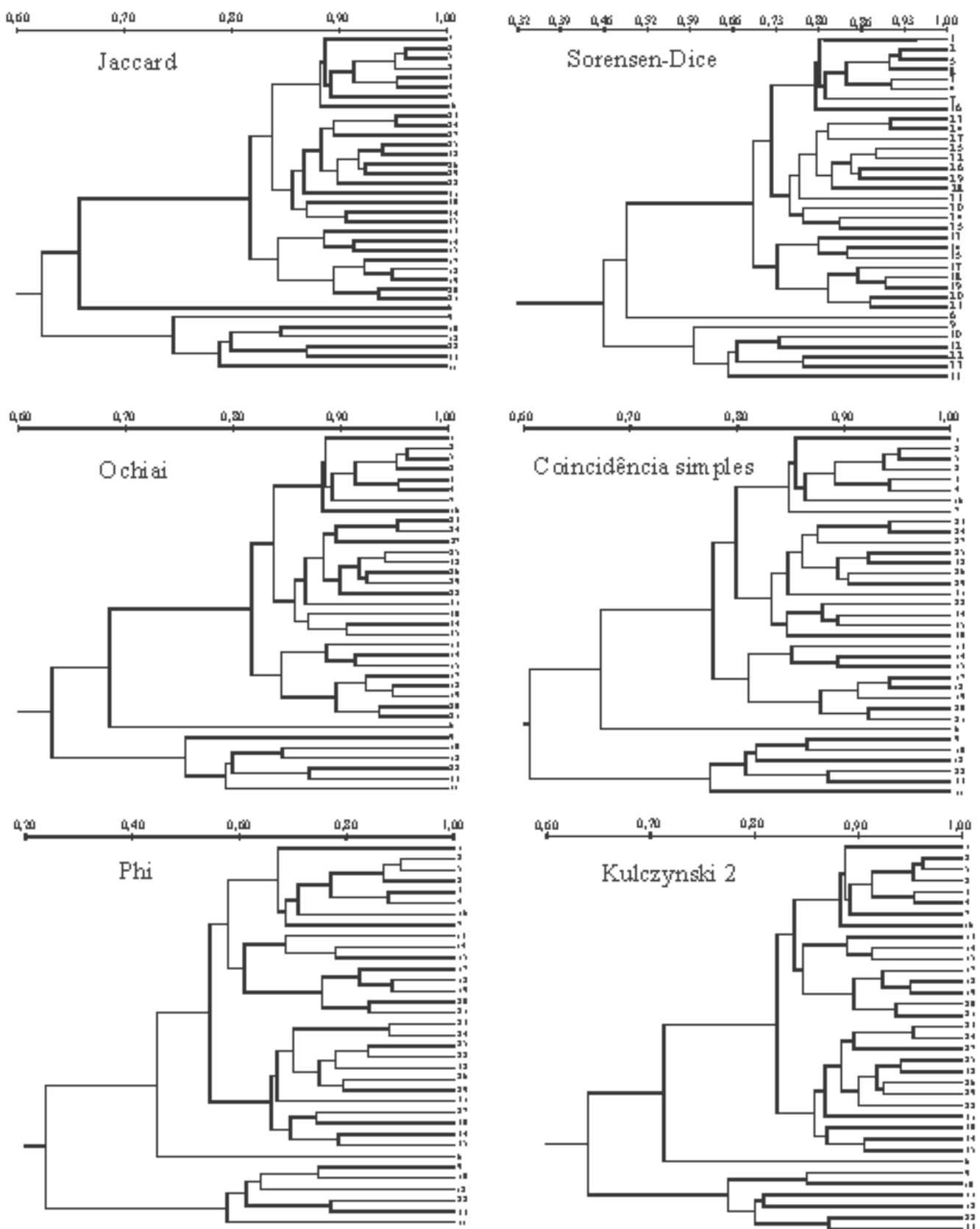

1: 05 OP PP; 2: 06 OP M; 3: 14 OP MP; 4: 15 OP EN; 5: 24 OP; 6: 25 BR M; 7: 26 OP P; 8: 30 OP P; 9: 36 BR MP; 10: 39 BR; 11: $42 \mathrm{AM} ; 12: 45 \mathrm{MO} ; 13: 54$ OP M; 14: 55 OP EN; 15: 56 OP; 16: 57 OP; 17: 58 OP P; 18: 60 OP P; 19: 60 OP M; 20: 61 OP P; 21: 61 OP M; 22: 62 MO; 23: Rio Tibagi; 24: Guateian 6662; 25: Macanudo; 26: Minuano; 27: Iapar 44; 28: Macotaço; 29: Guapo Brilhante; 30: FT Nobre; 31: FT 120; 32: Carioca; 33: Iraí; 34: FT 206; 35: Iapar 31.

Figura 1. Dendrogramas construídos a partir das matrizes de distâncias genéticas obtidas pelo complemento dos coeficientes de similaridade de Jaccard, Sorensen-Dice, Ochiai, Coincidência Simples, Phi e Kulczynski 2 entre cultivares locais e comerciais de feijão agrupadas pelo método da média aritmética não ponderada (UPGMA). 

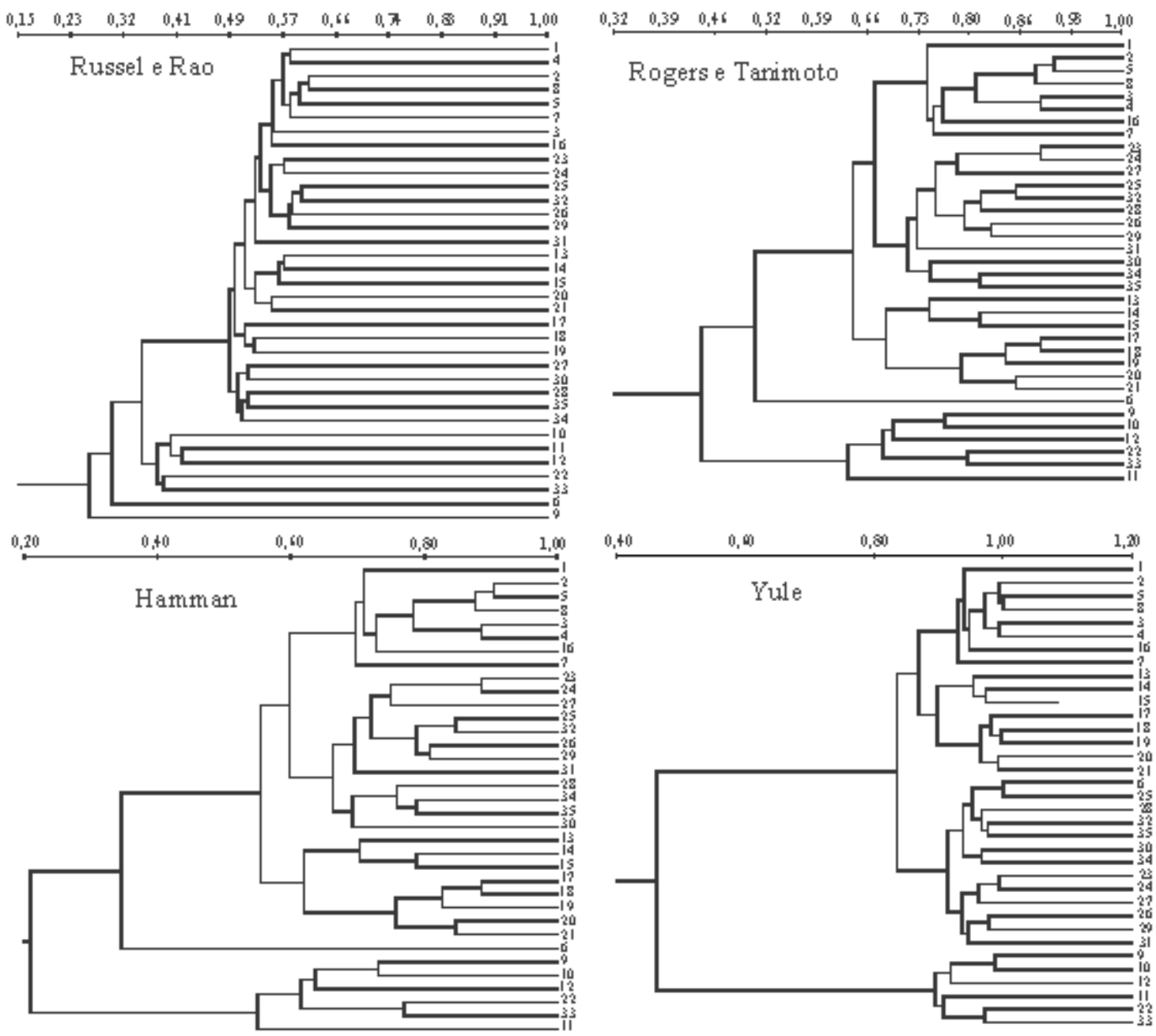

1:05 OP PP; 2: 06 OP M; 3: 14 OP MP; 4: 15 OP EN; 5: 24 OP; 6: 25 BR M; 7: 26 OP P; 8: 30 OP P; 9: 36 BR MP; 10: 39 BR; 11: 42 AM; 12: 45 MO; 13: 54 OP M; 14: 55 OP EN; 15: 56 OP; 16: 57 OP; 17: 58 OP P; 18: 60 OP P; 19: 60 OP M; 20: 61 OP P; 21: 61 OP M; 22: 62 MO; 23: Rio Tibagi; 24: Guateian 6662; 25: Macanudo; 26: Minuano; 27: Iapar 44; 28: Macotaço; 29: Guapo Brilhante; 30: FT Nobre; 31: FT 120; 32: Carioca; 33: Iraí; 34:FT 206; 35: Iapar 31.

Figura 2. Dendrogramas construídos a partir das matrizes de distâncias genéticas obtidas pelo complemento dos coeficientes de similiaridades de Russel e Rao, Rogers e Tanimoto, Hamman e Yule entre cultivares locais e comerciais de feijão agrupadas pelo método da média aritmética não ponderada (UPGMA).

grupos. No entanto, Rocha (2000), em estudos com batata, não verificou qualquer alteração no agrupamento e ordenamento das cultivares em relação aos oito coeficientes estudados.

Com base na análise dos dendrogramas, os coeficientes de similaridade separaram as 35 cultivares em dois grupos, correspondentes aos centros de domesticação, com exceção do coeficiente de Russel e Rao. Os mesmos coeficientes agruparam as cultiva- res comerciais (melhoradas) mesoamericanas em um mesmo subgrupo. Este fato evidencia o maior grau de similaridade entre estas cultivares, em decorrência, provavelmente, da preferência dos melhoristas pelo intercruzamento de cultivares elite que, como resultado, pode levar a um estreitamento da base genética da lavoura feijoeira no Rio Grande do Sul.

A eficiência de projeção das distâncias genéticas dos coeficientes de similaridade, em um espaço 
bidimensional, segundo os diferentes critérios (stress, distorção e correlação entre as distâncias originais e estimadas), apresentou alta variação (Tabela 3). Os coeficientes de Sorensen-Dice e Ochiai apresentaram os menores valores de stress, 27,4 e 27,6 , respectivamente, seguidos do coeficiente de Kulczinski 2, com 28,2, valores, segundo os critérios de Kruskal (1964), considerados regulares. Duarte et al. (1999) ao analisarem a eficiência de oito coeficientes, no agrupamento de cultivares de feijão, também encontraram maior eficiência em relação aos coeficientes de Ochiai e Sorensen-Dice, com valores de stress de 9,9 e 10,1, respectivamente.

A menor eficiência, e portanto os maiores valores de stress, foi observada com os coeficientes de Russel e Rao $(71,5)$ e Rogers e Tanimoto $(61,0)$, o que também está de acordo com os resultados obtidos por Duarte et al. (1999), cujo maior valor do stress foi observado pelo coeficiente de Russel e Rao $(56,5)$.

Nenhum dos dez coeficientes apresentou um bom nível de stress. Os coeficientes de Russel e Rao, Rogers e Tanimoto e Yule apresentaram níveis considerados insatisfatórios.

Considerando a base genética de marcadores RAPD, a ausência de amplificação de uma determinada banda em dois genótipos, não indica, necessariamente, similaridade genética entre eles. Desta forma, coeficientes que excluem a co-ocorrência negativa $(\mathrm{d}: 0,0)$ das expressões de similaridade tornam-se mais adequados no uso com marcadores deste tipo (Duarte et al., 1999).

Tabela 3. Eficiência da projeção das distâncias genéticas em um espaço bidimensional, por meio do grau de distorção, correlação entre distâncias originais e estimadas e valores de stress.

\begin{tabular}{lccc}
\hline Coeficiente & $\begin{array}{c}\text { Distorção } \\
(\%)\end{array}$ & $\begin{array}{c}\text { Correlação } \\
(\mathrm{r})\end{array}$ & $\begin{array}{c}\text { Stress } \\
(\%)\end{array}$ \\
\hline Jaccard & 37,3 & 0,941 & 38,4 \\
Sorensen-Dice & 25,1 & 0,960 & 27,4 \\
Russel e Rao & 70,3 & 0,866 & 71,5 \\
Ochiai & 24,6 & 0,955 & 27,6 \\
Coincidência Simples & 29,7 & 0,924 & 32,9 \\
Rogers e Tanimoto & 33,0 & 0,008 & 61,4 \\
Hamann & 29,3 & 0,925 & 32,5 \\
Kulczynski & 25,0 & 0,949 & 28,2 \\
Yule & 17,5 & 0,825 & 50,7 \\
Phi & 31,5 & 0,896 & 35,5 \\
\hline
\end{tabular}

Os resultados, de certa forma, refletem este fato, pois dos dez coeficientes estudados, os três de menor eficiência (Tabela 3), com valores de stress insatisfatórios, consideram em sua expressão de similaridade (Tabela 2) a co-ocorrência negativa (d), ao passo que os três de maior eficiência não a consideram.

Quanto ao agrupamento das cultivares pelo método de Tocher (Tabela 4) e análise do dendrograma (Figuras 1e 2), os dois coeficientes que apresentaram maior discrepância em relação aos demais, Russel e Rao e Yule, também são os únicos que consideram a co-ocorrência negativa somente no denominador de suas expressões, pois a excluem do numerador.

O método aglomerativo de otimização de Tocher tem sido utilizado no estabelecimento de grupos de indivíduos com o mesmo padrão de similaridade. Este método adota o critério de que a média das medidas de dissimilaridade dentro de cada grupo deve ser menor que as distâncias médias entre quaisquer grupos. O método requer a obtenção da matriz de dissimilaridade, que pode ser obtida por diferentes coeficientes e sobre a qual é identificado o par de indivíduos mais similar, que formará o grupo inicial (Cruz, 1997).

O número de grupos formados pelos diferentes coeficientes, pelo método de Tocher, variou de 2 a 18 grupos (Tabela 4). A classificação das cultivares dentro desses grupos também foi alterada. O coeficiente de Russel e Rao novamente apresentou o comportamento mais discrepante, separando as 35 cultivares em apenas dois grupos, enquanto os demais coeficientes formaram entre 16 e 18 grupos. Os coeficientes de Jaccard, Sorensen-Dice, Ochiai, Coincidência Simples, Kulczinski 2 e Phi apresentaram exatamente o mesmo número de grupos (18) e o mesmo ordenamento das cultivares nestes grupos. Duarte et al. (1999) também encontraram o mesmo padrão de agrupamento entre os coeficientes de Jaccard, Sorensen-Dice e Ochiai.

Quando se considera a expressão da similaridade desses seis coeficientes, observa-se que quatro deles (Jaccard, Sorensen-Dice, Ochiai e Kulczinski 2) não levaram em conta a co-ocorrência negativa, ao contrário dos outros dois, que a consideram (Tabela 1). Assim, em relação a eficiência desses coeficientes, é possível verificar que, mesmo não ha- 
vendo uma correspondência entre as expressões de similaridade dos coeficientes, eles produziram idêntico agrupamento das cultivares, o que não inviabiliza a utilização de tais coeficientes com marcadores RAPD.

Esses resultados justificam a subjetividade empregada, por diversos autores, na escolha do coeficiente de similaridade, já que de maneira geral não há grandes prejuízos e discrepâncias nos resultados gerados pelos vários coeficientes disponíveis. Desta forma, embora significativamente variáveis quanto aos parâmetros de similaridade considerados e o peso atribuído a eles nas expressões, todos os coeficientes, com exceção dos coeficientes de Russel e Rao, também criticado por Duarte et al. (1999), e de Yule, não apresentaram problemas quanto ao agrupamento dos genótipos, salvo pequenas alterações intragrupos, na análise dos dendrogramas, já comentadas.

No entanto, não somente o agrupamento dos genótipos deve ser levado em consideração no momento da escolha do coeficiente mais adequado. É importante que se tenha conhecimento da impor- tância relativa dos diferentes parâmetros de similaridade, considerados nos diversos coeficientes, em relação aos genótipos e aos caracteres em questão. Por exemplo, os coeficientes de Jaccard e Sorensen-Dice são idênticos em suas expressões, exceto que Sorensen-Dice atribui peso dobrado para a co-ocorrência positiva (Tabela 1), o que em certos casos pode ser importante.

Embora o coeficiente de Jaccard seja utilizado por grande número de pesquisadores em feijão (Vilarinhos et al., 1995; Alvarez et al., 1998; Briand et al., 1998; Skroch et al., 1998), arroz (Bonow et al., 2001) e batata (Rocha et al., 2001), e tenha apresentado, no presente trabalho, agrupamento das cultivares idêntico ao produzido por Sorensen-Dice e Ochiai na análise dos dendrogramas e no agrupamento de Tocher, revelou menor eficiência de projeção, o que o exclui como opção. Já os coeficientes de Sorensen-Dice, Ochiai e Kulczynski 2, mesmo tendo apresentado valores de stress considerados regulares, revelaram a melhor eficiência, menores distorção e stress e maiores correlações em relação aos demais, o que os torna mais adequados no estudo de

Tabela 4. Agrupamento de cultivares locais e comerciais de feijão pelo método de otimização de Tocher, considerando coeficientes de similaridade de Jaccard (J), Sorensen-Dice (SD), Russel e Rao (RR), Ochiai (O), Coincidência Simples (SM), Rogers e Tanimoto (RT), Hamann (H), Kulczynski 2 (K2), Yule (Y) e Phi (PHI) ${ }^{(1)}$.

\begin{tabular}{|c|c|c|c|c|c|c|c|c|c|c|}
\hline Grupo & J & SD & $\mathrm{RR}$ & $\mathrm{O}$ & SM & RT & $\mathrm{H}$ & K2 & $\mathrm{Y}$ & PHI \\
\hline $\mathrm{A}$ & 1,2 & 1,2 & $\begin{array}{c}1,3,5,7,9,11,13,15,17,19,21 \\
23,25,27,29,31,33,35\end{array}$ & 1,2 & 1,2 & 1,2 & 1,2 & 1,2 & 1,2 & 1,2 \\
\hline B & 3,5 & 3,5 & $\begin{array}{c}2,4,6,8,10,12,14,16,18,20,22 \\
24,26,28,30,32,34\end{array}$ & 3,5 & 3,5 & 3,4 & 3,5 & 3,5 & 3,5 & 3,5 \\
\hline $\mathrm{C}$ & 4,6 & 4,6 & & 4,6 & 4,6 & 5,6 & 4,6 & 4,6 & 4,6 & 4,6 \\
\hline D & 7,9 & 7,9 & & 7,9 & 7,9 & 7,8 & 7,9 & 7,9 & $7,9,11$ & 7,9 \\
\hline E & 8,10 & 8,10 & & 8,10 & 8,10 & 9,10 & 8,10 & 8,10 & $8,10,12,14$ & 8,10 \\
\hline $\mathrm{F}$ & 11,13 & 11,13 & & 11,13 & 11,13 & 11,12 & 11,13 & 11,13 & 13,16 & 11,13 \\
\hline G & 12,14 & 12,14 & & 12,14 & 12,14 & 13,14 & 12,14 & 12,14 & $15,18,20$ & 12,14 \\
\hline $\mathrm{H}$ & 15,17 & 15,17 & & 15,17 & 15,17 & 15,16 & 15,17 & 15,17 & 17,19 & 15,17 \\
\hline I & 16,18 & 16,18 & & 16,18 & 16,18 & 17,18 & 16,18 & 16,18 & 21,23 & 16,18 \\
\hline $\mathrm{J}$ & 19,21 & 19,21 & & 19,21 & 19,21 & 19,20 & 19,21 & 19,21 & 22,24 & 19,21 \\
\hline K & 20,22 & 20,22 & & 20,22 & 20,22 & 21,22 & 20,22 & 20,22 & 25,27 & 20,22 \\
\hline $\mathrm{L}$ & 23,25 & 23,25 & & 23,25 & 23,25 & 23,24 & $23,25,27$ & 23,25 & 26,28 & 23,25 \\
\hline M & 24,26 & 24,26 & & 24,26 & 24,26 & 25,26 & $24,29,31$ & 24,26 & 29,31 & 24,26 \\
\hline $\mathrm{N}$ & 27,29 & 27,29 & & 27,29 & 27,29 & 27,28 & 26,28 & 27,29 & 30,32 & 27,29 \\
\hline $\mathrm{O}$ & 28,30 & 28,30 & & 28,30 & 28,30 & 29,30 & 30,32 & 28,30 & 33,35 & 28,30 \\
\hline $\mathrm{P}$ & 31,33 & 31,33 & & 31,33 & 31,33 & 31,32 & 33,35 & 31,33 & 34 & 31,33 \\
\hline $\mathrm{Q}$ & 32,34 & 32,34 & & 32,34 & 32,34 & 33,34 & 34 & 32,34 & & 32,34 \\
\hline $\mathrm{R}$ & 35 & 35 & & 35 & 35 & 35 & & 35 & & 35 \\
\hline
\end{tabular}

(1)1: 05 OP PP; 2: 06 OP M; 3: 14 OP MP; 4: 15 OP EN; 5: 24 OP; 6: 25 BR M; 7: 26 OP P; 8: 30 OP P; 9: 36 BR MP; 10: 39 BR; 11: 42 AM; 12: $45 \mathrm{MO}$; 13: 54 OP M; 14: 55 OP EN; 15: 56 OP; 16: 57 OP; 17: 58 OP P; 18: 60 OP P; 19: 60 OP M; 20: 61 OP P; 21: 61 OP M; 22: 62 MO; 23: Rio Tibagi; 24: Guateian 6662; 25: Macanudo; 26: Minuano; 27: Iapar 44; 28: Macotaço; 29: Guapo Brilhante; 30: FT Nobre; 31: FT 120; 32: Carioca; 33: Iraí; 34: FT 206; 35: Iapar 31. 
divergência genética neste grupo de cultivares, com marcadores RAPD.

O mesmo não foi verificado por Rocha (2000) ao estudar a eficiência de diferentes coeficientes em batata, em que o coeficiente de Jaccard sobressaiuse sobre os demais, apresentando a melhor eficiência, ainda que Sorensen-Dice e Ochiai tenham ficado entre os três melhores coeficientes estudados.

\section{Conclusões}

1. Os coeficientes de Sorensen-Dice, Ochiai e Kulczynski 2 são os mais adequados no estudo da divergência genética entre genótipos de feijão analisados por meio de marcadores RAPD.

2. Os coeficientes de Russel e Rao e de Yule não são adequados para estudos de divergência genética entre genótipos de feijão por causa da baixa eficiência.

3. O coeficiente de Russel e Rao não é capaz de agrupar as cultivares em seus respectivos centros de domesticação, andino e mesoamericano.

\section{Referências}

ALVAREZ, M. T.; SÁENZ DE MIEIRA, L. E.; PÉREZ DE LA VEGA, M. Genetic variation in common and runner bean of the Northern Meseta in Spain. Genetic Resources and Crop Evolution, Dordrecht, v. 45, p. 243-251, 1998.

BONOW, S.; AUGUSTIN, E.; FRANCO, D. F.; PETERS, J. A.; TERRES, A. S. Caracterização isoenzimática de genótipos de arroz. Pesquisa Agropecuária Brasileira, Brasília, v. 36, n. 2, p. 291-300, fev. 2001.

BRIAND, L.; BROWN, A. E.; LENNÉ, J. M.; TEVERSON, D. M. Random amplified polymorphic DNA variation within and among bean landrace mixtures (Phaseolus vulgaris L.) from Tanzania. Euphytica, Wageningen, v. 102, p. 371-377, 1998.

CRUZ, C. D. Programa $\square$ GENES: aplicativo computacional em genética e estatística.Viçosa, MG: UFV, 1997. $442 \mathrm{p}$.

DINIZ FILHO, J. A. Métodos filogenéticos comparativos. Ribeirão Preto: Holos, 2000. 120 p.

DUARTE, J. M.; SANTOS, J. B. dos; MELO, L. C. Comparison of similarity coefficients based on RAPD markers in the common bean. Genetics and Molecular Biology, Ribeirão Preto, v. 22, n. 3, p. 427-432, 1999.
FERREIRA, M. E.; GRATTAPAGLIA, D. Introdução ao uso de marcadores moleculares em análise genética. 3. ed. Brasília: Embrapa-Cenargen, 1998. 220 p.

HARLAN, J. R.; DE WET, J. M. J. Toward a rational classification of cultivated plants. Taxon, Berlin, v. 20 , p. 509-517, 1971.

JACKSON, A. A.; SOMERS, K. M.; HARVEY, H. H. Similarity coefficients: measures for co-occurrence and association or simply measures of occurrence? American Naturalist, Chicago, v. 133, p. 436-453, 1989.

JOHNS, M. A.; SKROCH, P. W.; NIENHUIS, J.; KINRICHSEN, P.; BASCUR, G.; MUÑOZ-SCHICK, C. Gene pool classification of common bean landraces from Chile based on RAPD and morphological data. Crop Science, Madison, v. 37, p. 605-613, 1997.

KRUSKAL, J. B. Multidimensional scaling by optimizing goodness of fit to a non-metric hypothesis. Psychometrika, Baltimore, v. 29, p. 1-27, 1964.

MILLIGAN, G. W.; COOPER, M. An examination of procedures for determining the number of clusters in a data set. Psychometrika, Williamsburg, v. 50, p. 159-179, 1985.

ROCHA, B. H. G. Caracterização de genótipos e análise de pureza varietal em sementes de batata através de marcadores moleculares. 2000. 54 f. Tese (Doutorado em Ciência e Tecnologia de Sementes) - Universidade Federal de Pelotas, Pelotas, 2000.

ROCHA, B. H. G.; AUGUSTIN, E.; SILVA, J. B.; VIÉGAS, J. Isoenzymatic variability in wild potatoes. Pesquisa Agropecuária Brasileira, Brasília, v. 36, n. 5, p. 781-791, maio 2001 .

ROHLF, F. J. NTSYS-pe numerical taxonomy and multivariate analysis system: version 1.7. New York: Exeter Software, 1992. 236 p.

SKROCH, P. W.; NIENHUIS, J.; BEEBE, S.; TOHME, J.; PEDRAZA, F. Comparison of Mexican common bean (Phaseolus vulgaris L.) core and reserve germoplasm collections. Crop Science, Madison, v. 38, n. 2, p. 488-496, 1998.

TINGEY, S. V.; RAFALSKI, J. A.; WILLIANS, J. G. K. Genetic analysis with RAPD markers. In: APPLICATIONS OF RAPD TECHNOLOGY TO PLANT BREEDING SYMPOSIUM, 1993, Madison. Proceedings... Madison: Crop Science Society of America, 1993. p. 3-8.

VILARINHOS, A. D.; VIDIGAL, M. C.; BARROS, E. G. de; PAULA JUNIOR, T. J. de; CRUZ, C. D.; MOREIRA, M. A. RAPD-PCR characterization of varieties of the common bean (Phaseolus vulgaris L.) used to identify races of antracnose fungus (Colletotrichum lindemuthianum). Revista Brasileira de Genética, Ribeirão Preto, v. 18, p. 275-280, 1995. 